\title{
http://doi.org/10.15359/ree.2002-2.7 \\ DIVERSIDAD: RETOS PARA UNA EDUCACIÓN INCLUSIVA
}

\author{
M.Ed. Victor H. Bonilla Mata
}

Este articulo trata de la inclusión y la participación como requisitos para el desarrollo. La educación tiene pendiente, con la humanidad la otredad como proyecto social, asi como la urgencia de reconocer el contenido y significado histórico de la diversidad y la diferencia como un reto para la educación del siglo XXI.
This article deals with the inclusion and participation as requisites for development.

Education has a pending debt with humanity: the human diversity as a social project, and the urgency to acknowledge its content and historical meaning and the challenge the difference issue poses to education in the XXI century:

* Consultor independiente. Realiz6 estudios en Antropología Social en la Universidad de Costa Rica. Durante varios años fue profesor en la Universidad Internacional de Agricultura de la Región Tropical Húmeda (EAR'TH). Ha realizado publicaciones en temas como diversidad cultural, educación, desarrollo, ambiente, gestión local y otros. Actualmente es académico e investigador del Centro de Investigación y Docencia en Educacion (CIDE) de la Universidad Nacional donde realiz 6 sus estudios de Maestría en Educacion. 
La toma de conciencia de la

diversidad en estos tiempos no es

casual, ha sido un proceso

doloroso, de resistencias

registradas en la memoria épica

de muchos individuos y

sociedades. El reconocimiento a la

diversidad más que un ejercicio

académico es un llamado de

atención, sobre deudas

históricamente heredadas y

acumuladas como una cuenta

monumental que hay que saldar

con los hombres y mujeres de hoy

y mañana, con el ambiente y los

excluidos de este proyecto global.

Introducción

Vivimos en una época de transformaciones marcadas por los procesos globalizadores del capitalismo expansivo, que impone la fórmula del mercado como eje dinámico de las estructuras sociales, ante un mundo en el cual la mayoría mira atónita cómo los acontecimientos se suceden $\sin$ tener acceso a su control.

Fenómenos recientes, tanto en la Europa como en otras partes del globo, han llevado a hablar de cambios globales y de la forja de una aldea (no comunidad) glo'jal. Las argumentaciones empleadas para caracterizar estos fenómenos son, además de las de tipo político, el crecimiento y el empleo sorprendente de la informática, la telemática y las comunicaciones en las sociedades humanas actuales. Tales acontecimientos son interpretados y festejados por algunos, como aquellos que dan la razón de manera triunfal a la historia única del occidente etnocéntrico y etnocidiario, en su cúspide actual de neoliberalismo y globalización.

Estos son los vientos que nos anuncian los albores de este tercer milenio, con ideologías hegemónicas que nos llevan sin desvíos por los senderos de la modernización, aunque otros hablan de posmodernidad, para explicarnos las nuevas trampas de la colonización intelectual.

Sin embargo los otros, esas alteridades culturales, esas maneras colectivas de ser, que se resisten obcecadamente a dejar de ser, aunque no accedan a los caminos de la modernización, siguen ahí, se reproducen.

Acorde con los principios de occidente, esas alteridades debieron dejar de ser hace mucho tiempo, pero reaparecen. La evidencia no deja ninguna salida, los otros siguen estando ahí, renacen de sus propias cenizas. Se elabora entonces el discurso de la posmodernidad, como un reconocimiento fortuito a la alteridad, a la existencia y potencialidad de otros saberes, de otras visiones del mundo. Reconocimiento que no es más que una promesa coqueta de la posibilidad siempre abierta de incorporar la diferencia a la Historia Única, esa que habla de la 
superioridad incuestionable del occidente como Amo y Maestro. Como civilizador y educador de esa otredad que nos recuerda que la diversidad no es más que la expresión última de algún tipo de resistencia que se vivencia y escribe desde la diferencia.

$Y$ en éstas nos encontramos: por un lado, las fuerzas de la globalización necesariamente uniformadora y occidentalizadora. Por el otro, los silencios o las pequeñas voces de las otras lógicas, cuyo gran pecado es el ser y permanecer como un desafío de negación para occidente, y de esperanza para todos los demás, para nosotros. Los demás, que son indiscutiblemente mayoría y tienen otras ideas acerca de lo que debe ser la modernización o el "desarrollo"; de lo que debe ser, desde la cuenta de occidente, el principio de este tercer milenio de la humanidad.

La toma de conciencia de la diversidad en estos tiempos no es casual, ha sido un proceso doloroso, de resistencias registradas en la memoria épica de muchos individuos y sociedades. El reconocimiento a la diversidad más que un ejercicio académico es un llamado de atención, sobre deudas históricamente heredadas y acumuladas como una cuenta monumental que hay que saldar con los hombres y mujeres de hoy y mañana, con el ambiente y los excluidos de este proyecto global.

Será por esto que, organismos como la UNESCO (1996) y otros entendidos en materia educativa (Banco Interamericano de Desarrollo,1994), confíen que en la educación se encuentre el tesoro de los saberes y la posibilidad de un proyecto social más incluyente de la diferencia y un auténtico reconocimiento a la diversidad.

Una vez hecha esta ambientación de las ideas creo importante iniciar con una reflexión que permita devolverle la memoria histórica y la voz a la diversidad como construcción social y exorcizarla un poco de su estado de imaginario exótico, descontextualizado y desarticulado de los procesos sociohistóricos por los cuales transita.

Es tiempo de reconocer e interiorizar que la diversidad tiene historia pero también -y sobre todo- que tiene rostros.

¿Puede caracterizarse de alguna manera el transitar de la diversidad como sujeto social, histórico y cultural?, la respuesta es sí.

\section{La Diversidad: un concepto con historicidad a la luz de Lévi Strauss}

Parece ser que fue tan sólo en el siglo XVI cuando el problema de las discontinuidades culturales se planteó en la consciencia occidental de manera súbita y dramática, con el descubrimiento del Nuevo Mundo. Para aquella época la diferencia se redujo a una alternativa bastante sencilla y axiomática: "o bien los autóctonos americanos son hombres, y deben integrarse de grado o por fuerza a la civilización cristiana, o bien puede discutírseles su humanidad, con lo que participarían de la condición animal". 
Hay que esperar pues el siglo XVIII para que el problema sea planteado en términos de índole histórica y sociológica. $\mathrm{Y}$ aún así hay que señalar que, cualquiera que sea la solución propuesta, todos los autores, algunos de ellos llámense Condorcet, Diderot o Rousseau, están de acuerdo sobre las premisas, es decir, sobre la posibilidad de comparar las sociedades que mal llamaron primitivas o atrasadas, con la civilización occidental.

Esta visión unitaria del desarrollo de la humanidad, concebida ya como una progresión, ya como una regresión, o acaso como una mezcla compleja de las dos fórmulas, es aquella de la que sobre todo Auguste Comte denunciara la debilidad. En la lección 52 del Cours de philosophie positive, Comte critica, en efecto, los peligros de una filosofía unitaria del desenvolvimiento social y cultural. Es preciso -dice- estudiar el desarrollo como una propiedad específica de la civilización occidental, a reserva de adaptar ulteriormente las conclusiones obtenidas a la transformación, por afuera de sociedades diferentes.

Sin hacer un recuento exhaustivo, puedo decir que es a través del asombro, más que por un interés sistemático y desinteresado, que occidente despertó un tímido reconocimiento de la diferencia. Occidente inicia así su toma de conciencia de la diversidad, recordándole que el nosotros no es absoluto ni único. La otredad comienza a ocupar un lugar -no el más adecuado- e irrumpe en la agenda del control y la dominación de las sociedades colonialistas.

Si estamos de acuerdo en esto, entonces podemos planteamos el hecho social y cultural de que la diversidad es un concepto que se construye y puede explicarse sobre la base de realidades sociales, históricas, culturales, económicas e ideológicas concretas.

También puede que nos pongamos de acuerdo, con el hecho de que la diversidad, entonces, más que un concepto o un problema semántico, participa de estructuras de significación estrechamente relacionadas cuya existencia como construcción social, es susceptible de ser abordada e investigada como fenómeno social cultural innegable.

En este punto, podríamos preguntarnos cuál ha sido el papel de la educación en este proceso o inclusive qué tanto la diversidad ha permeado la educación como institución social. Al respecto nos referiremos a la escuela como gran crisol de la educación e institución social.

\section{La Diversidad como dualidad en la educación}

La escuela es una etapa dentro de una sucesión de instituciones especializadas. Los ritos de las sociedades antiguas, los mitos, y los chamanes; los templos y las castas sacerdotales; las escuelas sumerias, griegas, alejandrinas 
y romanas; las órdenes monásticas; las primeras universidades. Todas ellas han jugado un papel en la historia de los actuales sistemas escolares.

La especialización progresiva del contenido, el método, el personal, y la ubicación del aprendizaje humano socialmente organizado, constituye una de las tendencias históricas más instructivas. Dicho aprendizaje incluía originalmente mucho más de lo que hoy llamamos educación. Como saben, la escolarización incluye mucho menos.

Desde 1820 , la arqueología y la antropología han extendido la historia de la humanidad en decenas de millares de años. Hasta donde es posible comprobar, el ser humano siempre ha estado involucrado en actividades especializadas que tienen mucha relación con lo que sucede en las escuelas. Los ritos por ejemplo -prácticas simbólicas aparentemente innecesarias para la satisfacción de las necesidades materiales elementales- siempre han sido parte del repertorio humano. Los chamanes son un vivo ejemplo del rito de la enseñanza, combinando el papel del maestro con el del sacerdote, el mago, el actor, el artista, el poeta y el ideólogo.

Fundándose tanto en evidencias arqueológicas como antropológicas, parece que los ritos practicados en algunas sociedades antiguas participaban de ciertos elementos presentes en los currículos actuales. Tenían un protagonista de una edad determinada que representaba los mitos vinculados con el nacimiento, la adolescencia y la muerte, es decir, un modelo de maestro. Explicaban y celebraban tanto los aspectos cotidianos como los aspectos insólitos del mundo, o sea, un ideal de la cultura basado en un sistema de creencias y valores. Ofrecían actividades para los periodos ociosos que seguían a la caza o a las cosechas, una suerte de actividades extracurriculares. Permitían a los jóvenes probarse en los papeles de los adultos, comparable a la educación como agente de socialización y propiciador de un proyecto de vidá.

La invención de la escritura, que más o menos tuvo lugar al mismo tiempo que el establecimiento de las ciudades y las grandes religiones, surge probablemente de las manos de estos especialistas antiguos.

En la educación ateniense, particularmente en la impartida por Platón y Aristófanes, se encuentra mucho de los orígenes de la educación tutelar y.esa mutualidad que caracteriza a la actual educación cooperativa.

En fin, la educación surge íntimamente relacionada a la práctica y el desarrollo del culto y del gobierno como realidades sociales. El atrio del templo fue su hogar más antiguo; siendo los sacerdotes especializados sus primeros practicantes. Los chamanes y los sacerdotes constituyen -por tanto- un eje no sólo de los maestros y las escuelas sino también de la evolución de la humanidad. El cerebro, la mano, la lengua; la horda, la villa y la ciudad; la magia, la religión, el arte y la ciencia: son pilares del desarrollo físico, social y espiritual de la 
Participar activamente de un proyecto Pedagógico de la

Diversidad consiste entonces en el reconocimiento y luego comprensión de una humanidad plural. Esto supone a la vez una ruptura con la figura monótona de lo doble, con el "igual a sí mismos", con lo idéntico, y con la exclusión de un irreductible "otro" humanidad y de la educación como institución social. La diversidad ha estado acompañando y aportando en el proceso de desarrollo de la educación, corriendo el riesgo posterior de no ser auténticamente reconocida y comprendida.

En los ejemplos anteriores, percibamos los orígenes de la educación integral, del currículo como una visión de mundo para ser llevado a la práctica, de la

atención individualizada y las hoy llamadas adecuaciones curriculares, así como la práctica del acto pedagógico como un arte y una suerte de profesionalización de algunas áreas de la vida.

En los orígenes de la educación -entendida como una "relación entre iguales o mutual" - la diferencia y la diversidad son percibidas más cercanas a los acontecimientos cruciales de la vida, por lo tanto, más susceptibles de ser incluidas entre los contenidos que le caracterizaban. En la actualidad, la educación entendida como "institución social de saberes jerarquizados", gradualmente toma direcciones que dificultan la comprensión e inclusión real de la otredad. Emergiendo así del silencio obligado en nuestras sociedades con nombres como: género, indígena, campesino, nica, ambiente, SIDA, talibán, niño/niña de la calle, lesbiana, artista, colombiano, economía informal, homosexual, negro/negra, trabajadora/trabajador del sexo, punk, marginales, superdotados/superdotadas, discapacitados/discapacitadas, migrantes y hasta Hare Krishnas... la lista es larga.

La otredad nos emplaza y nos invita a repensar con humildad el instrumental teórico metodológico utilizado hasta hoy en el quehacer de la educación como ciencia. El reto de asumirnos con la otredad toca nuestras puertas reclamando el derecho a la inclusión y la participación en sociedades cada día más exclusivas, homogenizadoras e invisibilizadoras de la diferencia. La presencia innegable pero poco comprendida de la diversidad, se manifiesta. Se han hecho algunos esfuerzos pero los retos demandan mayores búsquedas, más comprometidas y sistemáticas.

Ya en este punto, inevitablemente, nos interrogan los “¿cómo?”, acosadores fantasmas de la deuda pendiente...

\section{Acercándonos a una Epistemología de la Diversidad}

Entre las interrogantes inmediatas podríamos citar: ¿Cómo aprehender la diversidad? ¿Cuál es su delimitación como objeto de estudio en la educación?, 
¿Cómo investigar la diversidad? ¿Por qué reconocernos en la diversidad? ¿Por qué la unidad en la diversidad? Y tantas otras.

Las respuestas, al igual que las preguntas, pueden ser muchas. No las responderemos aquí con ese aire mesiánico y civilizador que caracterizó históricamente a Occidente y su modelo educativo.

Con la honestidad del que se dispone a aprender, a ser reeducado, hay que explorar las fronteras de estos nuevos territorios del saber y buscar acercarnos a la construcción de una Epistemología de la Diversidad, acorde con nuestras realidades sociales y culturales.

Queremos arriesgar creativamente y sin temores, en la construcción de una epistemología de una disciplina científica que no se define mecánicamente por referencia a un objeto de estudio reificado, aislado de los procesos sociohistóricos que lo validan, sin referencia alguna a las transformaciones de la disciplina científica que se lo apropia. Avocarnos a la construcción del objeto de estudio, que señala las especificidades de los diferentes campos del saber, tanto como las articulaciones entre los mismos, nos refiere a un proceso de cambio permanente en el que se articulan dialécticamente los componentes sociohistóricos que en un momento determinado definen esa especificidad (tal como lo señalan Bourdieu et al, 1982).

Participar activamente de un proyecto Pedagógico de la Diversidad consiste entonces en el reconocimiento y luego comprensión de una humanidad plural. Esto supone a la vez una ruptura con la figura monótona de lo doble, con el "igual a sí mismos", con lo idéntico, y con la exclusión de un irreductible "otro".

El enfoque de una Pedagogía de la Diversidad implica, de esta manera, una verdadera revolución epistemológica, que comienza por una revolución de la mirada. Esto implica una explosión de la idea de que existe "un centro intelectual del mundo y del mundo en sí". El descubrimiento de la alteridad es el descubrimiento de una relación que nos permite abandonar el no identificar más nuestra pequeña provincia de humanidad con la humanidad en toda su extensión y de no lanzar más los pretendidos "diferentes" fuera de nuestra propia esencia.

Sensibles a lo extraño e inusual, una Pedagogía de la Diversidad, se interesaría en las nuevas y emergentes formas de organización del conocimiento, como: estructuras autogestionarias, grupos de redes de intercambio recíproco, fundamentos de las experiencias colectivas del aprendizaje, didácticas informales y otras. También en las experiencias colectivas actuales que puedan remozar la educación formal, como: las escuelas libres, el liderazgo compartido, modalidades de expresión de lo sagrado, experiencias educativas alternativas a nivel comunitario, nacional e internacional, y otras.

Una Pedagogía de la Diversidad fundamentaría su reflexión teórica, práctica y metodológica en una dialéctica que pone su operar entre las diferencias y las semejanzas, entre las necesidades colectivas y las individuales, entre la 
continuidad (la tradición) y la discontinuidad (el cambio, la transformación, la disidencia inclusive). Esa manera de actuar podría permitir plantearse de manera original la cuestión de la innovación pedagógica y del cambio educativo. Pero primordialmente-buscaría establecer mecanismos, procesos eficientesy efectivos de inclusión de la otredad.

Es un adentrarnos en la aplicación de metodologías cualitativas y transdisciplinarias que buscan la aprehensión de las estructuras significativas de los grupos sociales y los individuos. El reto de descentramos y abandonar el pensamiento dual, una oportunidad para renovar el instrumental teórico y metodológico, transformándonos en productores de tecnologías educativas totalizadoras del ser humano (Kilani, 1989). Es comprometernos y definir con qué nivel de interés y responsabilidad serán asumidos los retos que desde la otredad se plantean para la educación y en particular para la construcción inclusiva de una Pedagogía de la Diversidad.

\section{Referencias}

Banco Interamericano de Desarrollo (BID). (1994). A la búsqueda del Siglo XXI. Nuevos caminos de desarrollo en Costa Rica.

Bordieu, P. et al. (1982). El oficio del sociólogo. México D.F.: Siglo XXI.

Delors. J. (1996). La educación encierra un tesoro. Madrid: Santillana y UNESCO.

Kilani, M. (1989). “Introduction a l’ Antropologie”. En Camacho, J. (1995). Inédito.

Lévi-Strauss, C. (1990). Antropologíoa estructural: Mito, sociedad, humanidades. México D.F.: Siglo XXI.

Rimer, E. (1975). La escuela ha muerto: Alternativas en materia de educación. Barcelona: Barral Editores. 